\title{
Synthesis, Characterization and Biological Evaluation of Some Novel 1,3,4- Oxadiazole Derivatives as Potential Anticancer Agents
}

\author{
Akshay R. Yadav*, Shrinivas K. Mohite, Chandrakant S. Magdum
}

Department of Pharmaceutical Chemistry, Rajarambapu College of Pharmacy, Kasegaon, Maharashtra, India Corresponding author E-mail:- akshayyadav24197@gmail.com

\section{ABSTRACT}

A new Series of novel N-Substituted 1,3,4-Oxadiazole derivatives (2a-2f) were synthesized by the reacting 3,5dinitrobenzoic acid and subsequent treatment with thiourea by microwave assisted synthesis as green chemistry. Confirmation of the chemical structure of the synthesized compounds was substantiated by TLC, IR, ${ }^{1} \mathrm{HNMR}$, and MS spectroscopy. Synthesized compounds were screened for anticancer activity on MCF7 cell line. All synthesized compounds exhibit significant biological activity and certainly hold a greater promise for discovering potent biologically active molecules. Further the compounds $2 \mathrm{~b}, 2 \mathrm{c}$ and $2 \mathrm{e}$ has been moderate tested for its anticancer activity and out of these all, compound 2c showed most notable anticancer activity against breast cancer cell line. Molecules under study were analysed for ADME properties using SwissADME servers. ADME profiles were evaluated and most of the molecules were found to be suitable for further studies. In silico ADMET analysis is proved to be a good tool in drug discovery.

Keywords : 1,3,4-Oxadiazole, microwave, anticancer, MCF7, SwissADME

\section{INTRODUCTION}

Cancer is a disease in which uncharacteristic cells grow and proliferate in an uncontrolled manner. There are over 200 different cancer forms. There are over 60 different organs in the body that can develop cancer from nearly any cell type in the body. About 13 percent of all death worldwide is due to cancer, surpassing cardiovascular disease and taking number one place ${ }^{1}$. Breast cancer is the world's leading cause of cancer death and the most common cancer among women. There is significant variation in survival rates worldwide for breast cancer, where $80 \%$ are estimated to be below $40 \%$ for low-income countries in the high income countries for 5 years. Breast cancer is the world's leading cause of cancer death and the most common cancer among women. Cancer is a major prevalence is on rise. It is considered to be one of the leading causes of mortality due to diseases and the projected death toll due to cancer alone would touch approximately 10 million by the end year 20202. Oxadiazole is a heterocyclic compound containing one oxygen and two nitrogen atoms with several biological effects in five member rings and is thought to be the source of furan by combining two methane groups with two pyridine atoms in the form of nitrogen ${ }^{3-4}$. It is one of the versatile lead molecule to design potential biologically active agents. It found to exhibit diverse biological activities such as antimalarial, anti-inflammatory, antimicrobial, antiHIV, antitubercular, analgesic, anticonvulsant, Hypoglycemic and biological properties like genotoxic studies and lipid peroxidation inhibitor. 1,3,4-oxadiazole has been known that the activity of azo linkage increases with the incorporation of a suitable heterocyclic moiety ${ }^{5-6}$. Green chemistry is 
defined as the synthesis, design, development and application of chemical products to reduces hazardous substances. The application of green chemistry principles and practices renders regulation, control, clean-up, and remediation of the environment ${ }^{7} .1,3,4-$ oxadiazoles is a physiologically active nucleus and an imperative scaffold on which therapeutic molecules are designed and developed. In view of these observations, six novel oxadiazole derivatives were designed as potential and predicted to have strong therapeutic benefit as anticancer agents. The designed molecules were synthesized and evaluated for their anticancer activity ${ }^{8-13}$. To be effective as a drug, a potent molecule must reach its target in the body in sufficient concentration, and stay there in a bioactive form long enough for the expected biological events to occur. The new SwissADME web tool that gives free access to a pool of fast yet robust predictive models for physicochemical properties, pharmacokinetics, drug-likeness and medicinal chemistry friendliness, among which in-house proficient methods such as the BOILED Egg, iLOGP and Bioavailability Radar ${ }^{14}$.

\section{EXPERIMENTAL}

The starting synthesized compounds, 5-(3,5dinitrophenyl)-1,3,4-oxadiazole-2-amine was prepared by the reaction of 3,5-dinitrobenzoic acid with hydrazine hydrate and $\mathrm{CNBr}$ in presence of methanol and Conc. $\mathrm{H}_{2} \mathrm{SO}_{4}$ and substituted benzoyl isothiocyanate was prepared by substituted benzoyl chloride and ammonium thiocyanate in presence of acetone as a solvent result in formation of final desired compound $\mathrm{N}$-\{[5-(3,5-dinitrophenyl)-1,3,4oxadiazole-2-yl]carbamothioyl $\}$ derivatives was prepared by mixture of 5-(3,5-dinitrophenyl)-1,3,4oxadiazole-2-amine and benzoyl isothiocyanate in presence of acetone. The process in under green chemistry ${ }^{15}$.

\section{MATERIAL AND METHODS}

All chemicals and solvents were purchased from commercial sources like Research laboratory Mumbai and Loba chemie purified by distillation if necessary and residual water was removed and by using standard procedures and the reagents were purchased from S.D fine. The melting points of synthesized derivatives were determined in open capillary tube method. Thin layer chromatography was used to confirmed reaction and the purity of the intermediate and the final compounds by applying a single spot on TLC plate (silica gel G) using various solvents such as toluene, acetone, ethanol. TLC plates were visualized under iodine chamber. IR spectra were recorded on ATR JASCO FTIR-4600. 1H NMR spectra were performed in $\mathrm{CDCl}_{3}$ solution using Bruker $300 \mathrm{MHz}$ and their chemical shift are reported in $\delta$ unit with respect to TMS as internal standard at Diya lab, Airoli, Mumbai. Mass spectra were recorded on Pe sciex (model no. API 2000) software analyst 1.4.2 mode: Q1MS Q1/AUTO INJECTION from Diya lab, Airoli, Mumbai.

\subsection{General procedure for the Synthesis of 5-(3,5- dinitrophenyl)-1,3,4-oxadiazole-2-amine}

Methyl 3,5-dinitro benzoate was prepared by using 0.01 mole of 3,5-dinitrobenzoic acid in $20 \mathrm{ml}$ methanol. The reaction was heated in microwave under reflux for 10-15 min at 340 watt and by adding few drops of $\mathrm{H}_{2} \mathrm{SO}_{4}$ as catalyst. After completion of reaction solid was formed which was used for next step for the preparation of 3,5-dinitrobenzohydrazide. The mixture of above compound $(0.01 \mathrm{~mol})$ and $2 \mathrm{ml}$ of $99 \%$ hydrazine hydrate was refluxed for $5 \mathrm{~min}$ at 340 watt. After completion of reaction checked by TLC and solid precipitate was dried and recrystallize from methanol. The mixture of above 3,5dinitrobenzohydrazide $(0.01 \mathrm{~mol})$ in $15 \mathrm{ml}$ methanol and add Cyanogen bromide $(0.01 \mathrm{~mol})$ this reaction 
mixture was stirred and refluxed at 5-15 $\mathrm{min}$ at 340 watt and after completion of reaction checked by TLC. The solution was cooled and neutralized with $\mathrm{NaHCO}_{3}$. The solid precipitate was washed, dried and recrystallize from methanol.

\subsection{General procedure for the Synthesis of substituted benzoyl isothiocyanate}

A solution of substituted benzoyl chloride $(5 \mathrm{mmol})$ in acetone $(25 \mathrm{ml})$ was added dropwise to ammonium thiocyanate $(5 \mathrm{mmol})$ in acetone $(15 \mathrm{ml})$. The reaction mixture was heated under refluxed for 5-10 min at 340 watt. After completion of reaction checked by TLC. The reaction mixture was cooled at room temperature and the precipitate $\left(\mathrm{NH}_{4} \mathrm{Cl}\right)$ was filtered off. Solution of aroyl isothiocyanate derivative was prepared.

\subsection{General procedure for the Synthesis of $\mathrm{N}-\{[5-(3,5-$} dinitrophenyl)-1,3,4-oxadiazole-2-yl] carbamothioyl\} derivatives

A solution of 5-(3,5-dintrophenyl)-1,3,4-oxadiazole2-amine $(5 \mathrm{mmol})$ in acetone $(5 \mathrm{ml})$ was added and the resulting mixture was stirred with refluxed for 10-15 $\min$ at 340 watt after completion of reaction it was where, $\mathrm{R}=$ checked by TLC. The solid product was washed with water and purified by washing with methanol.
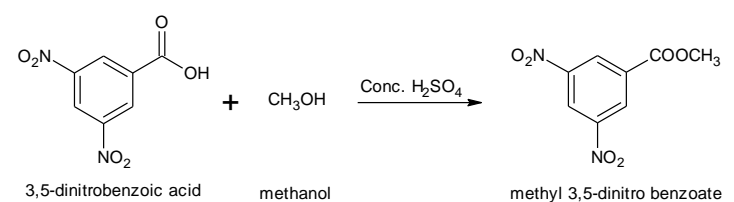

methyl 3,5-dinitro benzoate

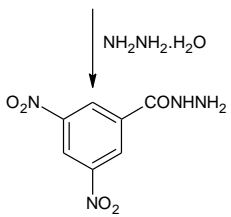

3,5-dinitrobenzohydrazide $\mathrm{CNBr}$
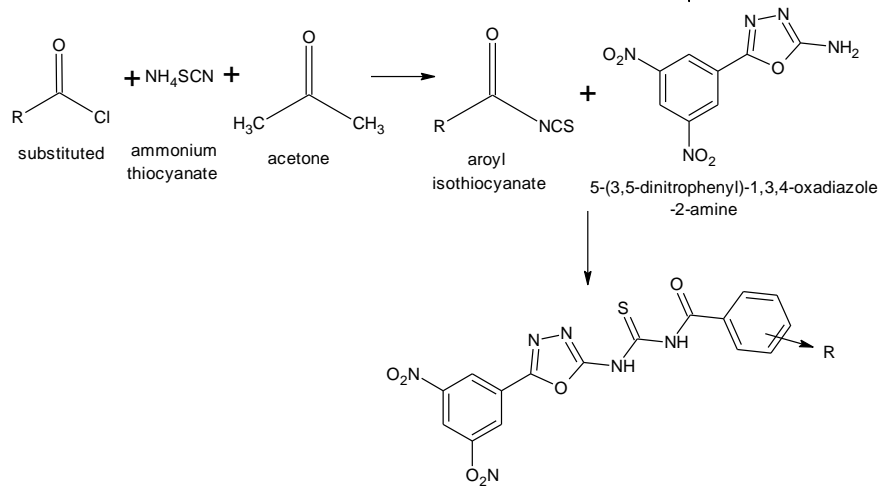

$\mathrm{N}-\{(5-(3,5-$ dinitrophenyl)-1,3,4-oxadiazole-2-yl] carbamothioyl\} -4-substituted benzamide derivatives $(2 a-f)$

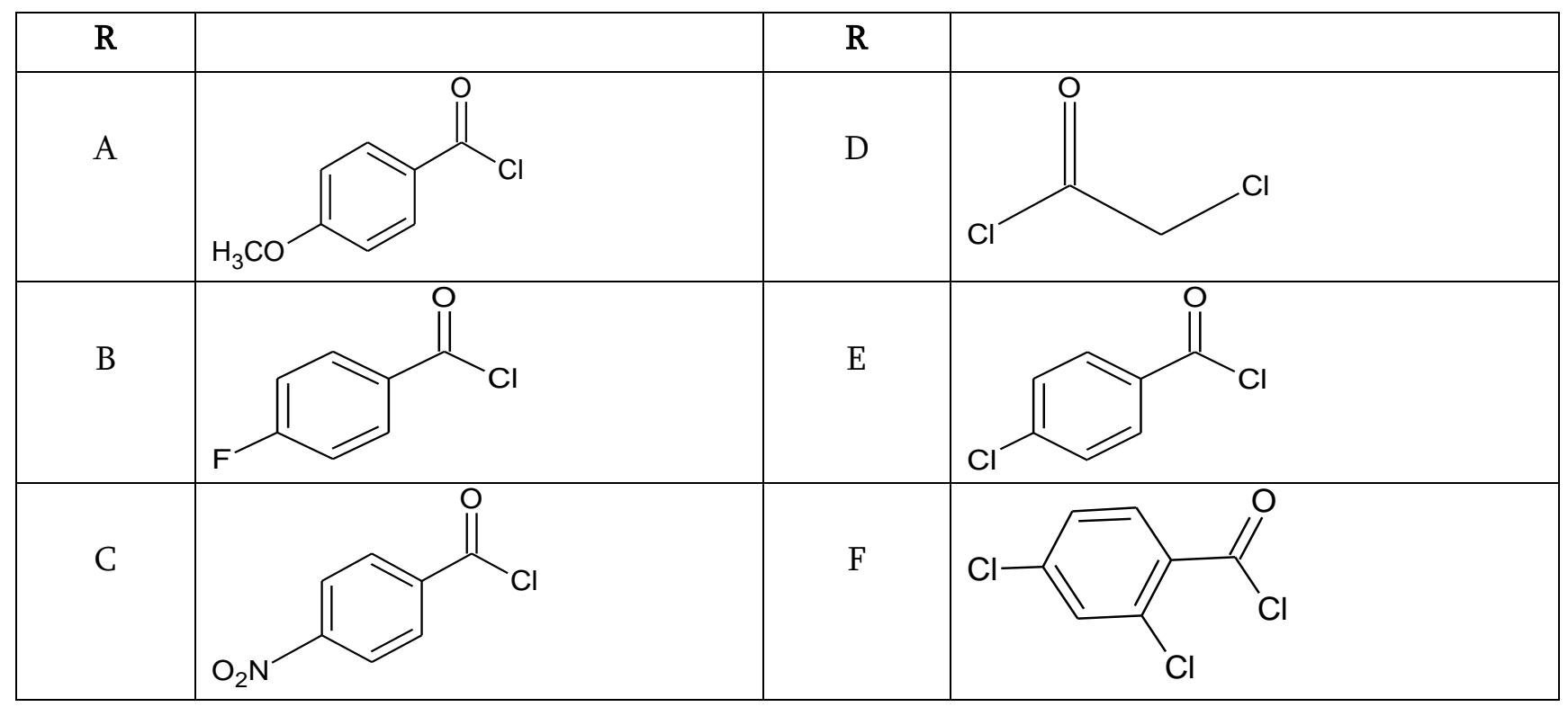

Scheme 1 Synthetic route for the preparation of the title compound (2a-f) 
(2a) N-\{[5-(3,5-dinitropenyl)-1,3,4-oxadiazol-2-yl] carbamothioyl\}-4-methoxybenzamide

Brown solid; 78\% yield, m.p. $155-157^{\circ} \mathrm{C}$; IR ( $\mathrm{KBr} \mathrm{cm}^{-}$ 1): 3158 (N-H str.), 1921 (C=C stretch), 3164 (C-H str.) $1604(\mathrm{~N}-\mathrm{Cl}), 715$ (C-Cl stretch) : 1H NMR $(400 \mathrm{MHz}$, DMSO-d6): 7.262-7.358 (4H-C=O near benzene) ; 1.027 (3=CH-O)3.9755 (1=C-NH (aromatic); 8.476 (1=C-NH sec amide); 7.840-8.452 (3H=O, oxadiazole near-benzene): $\mathrm{MS}(\mathrm{m} / \mathrm{z}+)[\mathrm{M}+]$ 444; For $\mathrm{C}_{17} \mathrm{H}_{12} \mathrm{~N}_{6} \mathrm{O}_{7} \mathrm{~S}$

(2b) N-\{[5-(3,5-dinitropenyl)-1,3,4-oxadiazol-2-yl] carbamothioyl\}-4-fluorobenzamide

White solid; $69.04 \%$ yield, m.p. $165-167{ }^{\circ} \mathrm{C}$; IR ( $\mathrm{KBr}$ $\left.\mathrm{cm}^{-1}\right)$ : 3156 (N-H str.), 1927 (C=C stretch), 3170 (C-H str.), 1606 (N-Cl), 1032 (C-F stretch) : 1H NMR (400MHz, DMSO-d6): 7.269-7.355 (4H-C=O near benzene) ; 3.9762 (1=C-NH (aromatic); 8.576 (1=C$\mathrm{NH}$ sec amide); 7.840-8.452 ( $3 \mathrm{H}=\mathrm{O}$, oxadiazole nearbenzene): $\mathrm{MS}(\mathrm{m} / \mathrm{z}+)[\mathrm{M}+]$ 432; For $\mathrm{C}_{16} \mathrm{H}_{9} \mathrm{FN}_{6} \mathrm{O}_{6} \mathrm{~S}$

\section{(2c) N-\{[5-(3,5-dinitropenyl)-1,3,4-oxadiazol-2-yl]} carbamothioyl\}-4-nitrobenzamide

Brown solid; 74\% yield, m.p. $140-142{ }^{\circ} \mathrm{C}$; IR ( $\mathrm{KBr} \mathrm{cm}^{-}$ 1): 3156 (N-H str.), 1927 (C=C stretch), 3170 (C-H str.), 1400 (N-O str.), 1712 (C=O stretch) : 1H NMR (400MHz，DMSO-d6): 7.452-7.559 (4H-C=O near benzene) ; 3.662 (1=C-NH (aromatic); 8.541 (1=C-NH sec amide); 7.841-8.459 (3H=O, oxadiazole nearbenzene): $\mathrm{MS}(\mathrm{m} / \mathrm{z}+)[\mathrm{M}+]$ 459; For $\mathrm{C}_{16} \mathrm{H}_{9} \mathrm{~N}_{7} \mathrm{O}_{8} \mathrm{~S}$.

(2d) N-\{[5-(3,5-dinitropenyl)-1,3,4-oxadiazol-2-yl] carbamothioyl\}-acetamide

Brown solid; 69\% yield, m.p. $155-157{ }^{\circ} \mathrm{C}$; IR ( $\mathrm{KBr} \mathrm{cm}^{-}$ 1): 3159 (N-H str.), 1921 (C=C stretch), 3160 (C-H str.), 1402 ( $\mathrm{N}-\mathrm{O}$ str.), 1700 (C=O str), 650 (C-Cl str): $1 \mathrm{H}$ NMR (400MHz, DMSO-d6): $3.620 \quad$ (2=C-NH (aromatic); 8.534-8.978 (1=C-NH sec amide): MS $(\mathrm{m} / \mathrm{z}+)[\mathrm{M}+]$ 387; For $\mathrm{C}_{11} \mathrm{H}_{7} \mathrm{ClN}_{6} \mathrm{O}_{6} \mathrm{~S}$ (2e)

4-chloro-N-\{[5-(3,5-dinitropenyl)-1,3,4oxadiazol-2-yl] carbamothioyl\}-benzamide

White solid; 87\% yield, m.p. $143-145{ }^{\circ} \mathrm{C}$; IR ( $\mathrm{KBr} \mathrm{cm}$ 1): 3250 ( $\mathrm{N}-\mathrm{H}$ str.), 1621 (C=C stretch), 3364 (C-H str.), 1604 ( $\mathrm{N}-\mathrm{Cl}), 738$ (C-Cl stretch) : 1H NMR $(400 \mathrm{MHz}$, DMSO-d6): 7.275-7.369 (4H-C=O near benzene) ; 1.042 (3=CH-O); 3.8755 (1=C-NH (aromatic); 8.562 (1=C-NH sec amide); 7.851-8.448 (3H=O, oxadiazole near-benzene): $\quad$ MS $\quad\left(\mathrm{m} / \mathrm{z}^{+}\right)[\mathrm{M}+] \quad 449 ; \quad$ For $\mathrm{C}_{16} \mathrm{H}_{9} \mathrm{ClN}_{6} \mathrm{O}_{6} \mathrm{~S}$

(2f) 2,4-dichloro-N-\{[5-(3,5-dinitropenyl)-1,3,4oxadiazol-2-yl]carbamothioyl\}benzamide

White solid; $80 \%$ yield, m.p. $143-145{ }^{\circ} \mathrm{C}$; IR $\left(\mathrm{KBr} \mathrm{cm}^{-}\right.$ 1): 3250 (N-H str.), 1630 (C=C stretch), 3359 (C-H str.), 1601 ( N-Cl), 730 (C-Cl stretch) : 1H NMR (400MHz, DMSO-d6): 7.268-7.350 (3H-C=O near benzene); 1.042 (1=CH-O); 3.8652 (1=C-NH (aromatic); 8.540 (1=C-NH sec amide); 7.848-8.441 $(3 \mathrm{H}=\mathrm{O}$, oxadiazole near-benzene): $\quad \mathrm{MS} \quad(\mathrm{m} / \mathrm{z}+)[\mathrm{M}+] \quad 483 ; \quad$ For $\mathrm{C}_{16} \mathrm{H}_{8} \mathrm{Cl}_{2} \mathrm{~N}_{6} \mathrm{O}_{6} \mathrm{~S}$

\subsection{Anticancer activity:}

The chemicals were purchased from research lab, Mumbai, India. And the solvent were purified by distillation process. The test of 1,3,4-oxadiazole derivatives were synthesized in our laboratory. MCF7 cell line obtained from National Centre for Cell Sciences (NCCS), Pune. The cells were cultured at $37^{\circ} \mathrm{C}$ in a humidified atmosphere of $5 \%$ CO2 incubator.

\section{Pharmacology}

The tryphan blue exclusion test is used to determine the number of viable cells present in a cell suspension. It is based on the principle that live cells possess intact cell membranes that exclude certain dyes like tryphan blue. When a cell suspension is simply mixed with the dye and then visually examined to determined whether cells take up or exclude dye. A viable cell will have a clear cytoplasm whereas a 
nonviable cell will have a blue cytoplasm. It is useful tool in various experiment procedures, including those for tumour susceptibility, microbiological resistance, and spontaneous cell death after submission to different experimental conditions ${ }^{16-17}$.

Method: Tryphan blue exclusion method

Place $50 \mu \mathrm{l}$ of cell suspension in cryo-vial. Add equal parts of $0.4 \%$ tryphan blue dye to the cell suspension to obtain a 1 to 2 dilution (example: $50 \mu$ of cells to $\mu$ l of tryphan blue) and mix by pipetting up and down. Incubate the mixture for less than three minutes at room temperature. If cells are counted after approximately five minutes, viability will be inaccurate due to the cell death. With the cover slip already in place, fill one side of a hemocytometer counter with the cell suspension by placing the tip of the pipette at the notch. Typically, each side will take 10 to $20 \mu \mathrm{l}$. Place the hemocytometer on the stage of a motic microscope and focus onto the cells. Each side of the hemocytometer contains multiple squares. Count all cells in each squares in each corner of the hemocytometer. Each large square contains 16 small squares. In each large square count cells that are on the border lines on two sides only. Keep track of the number of the blue cells seperatly as well as part of the complete number of cells.

To calculate the number of viable cells $/ \mathrm{ml}$ : Take the average cell count from each of the sets of 16 corner squares. Multiply by $10,000\left(10^{4}\right)$. Multiply by 5 to correct for the 1:5 dilutions from the Trypan Blue addition.

To calculate viability: If both live and dead cell counts have been recorded for each set of 16 corner squares, estimate viability can be calculated. Add together the live and dead cell count to obtain a total cell count. Divide the live cell count by the total cell count to calculate the percentage viability.

\subsection{Pharmacokinetics and drug-likeness prediction by SwissADME}

The ADME study was carried out using SwissADME predictor. This is a free web tool to evaluate the pharmacokinetics, drug likeness and medicinal chemistry friendliness small molecules. As mentioned earlier, the attention was given to design the molecules which fit into the rule of drug likeness. The properties like molecular weight less than $500 \mathrm{~g} / \mathrm{mol}$, less than 5 numbers of hydrogen bond donors, less than 10 numbers of hydrogen bond acceptors and less than 10 rotatable bonds were chosen as criteria, while the selection of molecules to be synthesized (Doak et al., 2014). The search engine further gave a compiled result on Solubility, GI absorption, BBB permeability and bioavailability of these molecules $b . \log P$, a measure of lipophilicity of the molecule is the logarithm of the ratio of the concentration of drug substance between two solvents in an unionized form. Lipinski rule prescribes an upper limit of 5 for druggable compounds. The lower the $\log \mathrm{P}$ values the stronger the lipophilicity for the chemical substance. The aqueous solubility of a compound significantly affects its absorption and distribution characteristics ${ }^{18-}$ 20.

\section{RESULT AND DISCUSSION}

\subsection{Anticancer activity}

Anticancer activity of Synthesized compound was tested using trypan blue exclusion method. 5Fluorouracil used as standard anticancer drug. By performing anticancer activity it has been noted \% inhibition of standard drug is 5-fluroruracil and by comparing with test sample (2a-2f) in that compound $2 c$ shows significant activity. It was observed that presence of nitro(- $\left.\mathrm{NO}_{2}\right)$ functional group in molecule was favourable for enhanced anticancer activity. The results obtained by performing anticancer activity are listed in Table No. 1. 
Table 1: Anticancer activity of synthesized compound (2a-f) against MCF-7 cell line.

\begin{tabular}{|c|c|c|c|c|}
\hline \multirow{2}{*}{ Sr.no } & Compound & \multicolumn{3}{|c|}{ \% Viability } \\
\cline { 3 - 5 } & Code & $\mathbf{1 0} \mathbf{~ m c g}$ & $\mathbf{5 0} \mathbf{~ m c g}$ & $\mathbf{1 0 0} \mathbf{~ m c g}$ \\
\hline 1 & $2 \mathrm{a}$ & 79.75 & 80.56 & 77.28 \\
\hline 2 & $2 \mathrm{~b}$ & 83.69 & 77.44 & 77.23 \\
\hline 3 & $2 \mathrm{c}$ & 85.21 & 81.56 & 78.67 \\
\hline 4 & $2 \mathrm{~d}$ & 79.23 & 77.14 & 74.91 \\
\hline 5 & $2 \mathrm{e}$ & 82.14 & 80.13 & 78.50 \\
\hline 6 & $2 \mathrm{f}$ & 77.96 & 74.73 & 73.71 \\
\hline 7 & Std (5-FU) & $\mathbf{8 7 . 7 8}$ & $\mathbf{8 4 . 2 4}$ & $\mathbf{8 2 . 1 4}$ \\
\hline
\end{tabular}

\subsection{Pharmacokinetics and drug-likeness prediction by SwissADME}

The results obtained from in silico studies clearly indicate compound code (2a-f) with different group substitution is the most druggable substance showing good ADME properties. The results obtained from the SwissADME search engine are listed in Table No. 2.

Table 2: Pharmacokinetics and drug-likeness predictions for the synthesized compounds (2a-f) by SwissADME

\begin{tabular}{|c|c|c|c|c|c|c|c|}
\hline $\begin{array}{c}\text { Sr. } \\
\text { no }\end{array}$ & $\begin{array}{c}\text { Comp } \\
\text { Code. }\end{array}$ & $\begin{array}{c}\text { Mol. } \\
\text { wt }\end{array}$ & Solubility & $\begin{array}{c}\text { GI } \\
\text { absorption }\end{array}$ & $\begin{array}{c}\text { Log Kp } \\
(\mathbf{c m} / \mathbf{s e c})\end{array}$ & $\begin{array}{c}\text { BBB } \\
\text { permeability }\end{array}$ & Bioavailability \\
\hline 1 & $2 \mathrm{a}$ & 444 & $\begin{array}{c}\text { Moderately } \\
\text { soluble }\end{array}$ & High & -3.12 & No & 0.11 \\
\hline 2 & $2 \mathrm{~b}$ & 432 & soluble & High & -5.23 & No & 0.11 \\
\hline 3 & $2 \mathrm{c}$ & 459 & soluble & High & -3.45 & No & 0.11 \\
\hline 4 & $2 \mathrm{~d}$ & 387 & $\begin{array}{c}\text { Moderately } \\
\text { soluble }\end{array}$ & High & -4.12 & No & 0.11 \\
\hline 5 & $2 \mathrm{e}$ & 449 & $\begin{array}{c}\text { Moderately } \\
\text { soluble }\end{array}$ & High & -5.65 & No & 0.11 \\
\hline 6 & $2 \mathrm{f}$ & 483 & soluble & High & -3.87 & No & 0.11 \\
\hline
\end{tabular}




\section{CONCLUSION}

A series of novel 1,3,4-oxadiazole derivatives (2a-2f) was synthesized by microwave assisted reaction under green chemistry and gives desirable yield. The results of Anticancer activity highlighted that tested compound 2c exhibited significant activity by tryphan blue exclusion method. The SwissADME web tool enables the computation of key physiochemical, pharmacokinetic, drug-like and related parameters for one or multiple molecules. Screening process with drug-likeness rules showed that compounds meet the criteria of drug likeness. It was interesting to note the SwissADME prediction results also in coherence with final results.

\section{ACKNOWLEDGEMENT}

I express my sincere thanks to Vice-principal Prof. Dr. S. K. Mohite and Principal Prof. Dr. C. S. Magdum for providing me all necessary facilities and valuable guidance extended to me.

\section{VII.REFERENCES}

[1]. Ahsan M, Rathod V, Singh V, Singh M , Sharma R, Jadhav S, Yasmin S, Kumar P, "Synthesis, anticancer and molecular docking studies of 2(4-chlorophenyl)-5-aryl-1,3,4-oxadiazole analogues". 2013. Med chem. 3(4): 294-297.

[2]. Shah R, Rosso K, Nathanson S, "Pathogenesis, prevention, diagnosis and treatment of breast cancer". 2014. world J Clin Oncol. 5(3): 283298.

[3]. Bala S, Khamboj S, Kajal A, Saini V, Prasad D, "1,3,4-oxadiazole derivatives: Synthesis, characterization, antimicrobial potential, and computational studies”. 2014. Bio med Res Int: $1-18$.
[4]. Rashid M, Husain A, Mishra R, Karim S, Khan S, Ahmad M, Al-wabel N, Husain A, Ahmed A, Khan S, "Design and synthesis of benzimidazoles containing substituted oxadiazole, thiadiazole and triazolo-thiadiazines as a source of new anticancer agents". 2015. Arab. J. Chem: 1-23.

[5]. Shridhar A, Keshavayya, Peethamber, Hoskeri $\mathrm{H}$, " Synthesis and biological activites of Bis alkyl 1,3,4-oxadiazole incorporated azo dye derivatives". 2012. Arab. J. Chem: 1-6.

[6]. Chandrakantha B, Shetty P, Nambiiyar V, Isloor $\mathrm{N}$, Isloor A, "Synthesis, characterization and biological activity of some new 1,3,4-oxadiazole bearing 2-fluoro-4-methoxy phenyl moiety". 2010. Eur. J. Med. Chem. 45: 1206-1210.

[7]. Yadav A, Mohite S, "Design, Synthesis and Characterization of Some Novel benzamide derivatives and it's Pharmacological Screening". 2020. Int J Sci Res Sci Technol. 7(2): 68-74.

[8]. Gaonkar S, Rai K, Prabhuswamy, "Synthesis and antimicrobial studies of a new series of 2-\{4-2(5-ethylpyridin-2-yl)ethoxy]phenyl\}-5substituted-1,3,4-oxadiazoles". 2006. Eur. J. Med. Chem. 41: 841-846.

[9]. Vishwanathan B, Gurupadayya B, Sairam V, Inturi $\mathrm{B}$, "Design, synthesis, in vitro antioxidant and in vivo anti-inflammatory activities of novel oxadiazole derivatives". 2014. Int J Pharm Pharm Sci. 6(9): 514-520.

[10]. Ali S, Jabbir A, Rana A, Mohsie B, "Synthesis of Some Sulfa drugs Derivatives as Antibacterial Agent" 2016, Micro. J. Ap. Sci. 5: 75-83.

[11]. Patel M, Modi N, Ravalb J, Menon S, "Calix4]arene based 1,3,4-oxadiazole and thiadiazole derivatives: Design, synthesis, and biological evaluation" 2012, Org. Biomol. Chem. 10: 1785-1794

[12]. Salih N, Salimon J, Yousif E, "Synthesis and Antimicrobial Evaluation of 5-(p-substituted 
phenyl)-N-(3-(5-nitrofur-2-yl) allylidene)1,3,4-thiadiazol-2-amine Derivatives", 2011, Orient. J. Chem. 27(2): 373-383.

[13]. Yamada N, Kataoka $Y$, Nagami T, Hong S, Kawai S, Kuwano E, "5-Aryl-1,3,4-oxadiazole2-thiols as a New Series of trans-Cinnamate 4Hydroxylase Inhibitors", 2004, J. Pestic. Sci. 29(3),: 205-208

[14]. Daina A, Michielin O, Zoete V, "SwissADME: a free web tool to evaluate pharmacokinetics, druglikeness and medicinal chemistry friendliness of small molecules" Sci. Rep:1-13.

[15]. Subbhaiah N, Mohanty S, Sudha B, Ayyana C, "Synthesis, characterization and evaluation of antibacterial \& anti-fungal activity of 2,5disubstituted 1,3,4-oxadiazole derivatives". 2016. Int J Pharm Pharm Sci. 1(2) : 39-42.

[16]. Cell viability testing with tryphan exclusion method, social \& scientific systems, INC. National institute of environmental health sciences:1-2.

[17]. Freitas B, Almeida V, Pinto M, Mourao F, Massensini A, Filho O, Viera E, Melo G, “ Tryphan blue exclusion assay by flow cytometry”. 2014. Braz J Med Biol. 47(4): 307315.

[18]. Lohidashan K, Rajan, Andhale G, Paul M, Jerin J, "Pass and Swiss ADME collaborated in silico docking approach to the synthesis of certain pyrazoline spacer compounds for dihydrofolate reductase inhibition and antimalarial activity”.2018. Bangladesh J Pharmacol. 13: 2329.

[19]. Ali A, Badawy M, Shah R, Rehman W, Kilney Y, Ashry E, Tahir N," Synthesis, characterization and In-Silico ADMET Screening of Mono-Di-carbomethoxylated 6,6'Methylrnrbis(2-cyclohexyl-4-methylphenol) and their hydrazides and hydrazones". 2017. Der Chem. Sin. 8(4): 446-460.
[20]. Kumar R, Giri A, Nadendla R, "Insilico ADME profiling of CDK9 inhibitors". 2018. J Sci Res Pharm. 7(3):30-34.

\section{Cite this article as :}

Akshay R. Yadav, Shrinivas K. Mohite, Chandrakant S. Magdum, "Synthesis, Characterization and Biological Evaluation of Some Novel 1,3,4-Oxadiazole Derivatives as Potential Anticancer Agents", International Journal of Scientific Research in Science and Technology (IJSRST), Online ISSN : 2395-602X, Print ISSN : 2395-6011, Volume 7 Issue 2, pp. 275-282, March-April 2020. Available at doi : https://doi.org/10.32628/IJSRST207234 Journal URL : http://ijsrst.com/IJSRST207234 